\title{
Implementasi Web Portal Pageraji.info Untuk Mengangkat Potensi Desa Pageraji Kecamatan Cilongok Kabupaten Banyumas
}

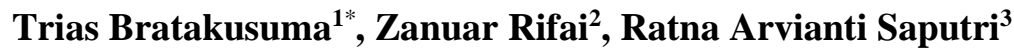 \\ 1,2,3 Program Studi Sistem Informasi, Universitas Amikom Purwokerto, Indonesia \\ Email: 'brata@amikompurwokerto..ac.id, ${ }^{2}$ zanuar.rifai@amikompurwokerto.ac.id, ${ }^{3}$ arvi@gmail.com
}

\section{INFORMASI ARTIKEL}

\section{Data artikel:}

Naskah masuk, 03 Desember 2019

Direvisi, 11 Januari 2020

Diterima, 16 Januari 2020

\section{Kata Kunci:}

Desa

Potensi Desa

Web Portal

\begin{abstract}
ABSTRAK
Abstract- The village is a community that has the authority to regulate and regulate the community on the basis of proposals and customs as precisely as discussed in the national government system and is in the Regency. Each village has different potential. Village Potential is all natural resources and human resources that are provided at the same time stored in the Village. Pageraji Village is located in the West of the Capital City of Banyumas Regency with a distance of approximately $9 \mathrm{~km}$ and consists of lowland and plateau areas bordering the North of Langgongsari Village, East of Langgongsari Village and Pejogol Village, in the South of Jatisaba Village, Kasegeran Village and Desa Sudimara, west of Cilongok Village and Pernasidi Village. The current economic condition of Pageraji Village is supported by the agriculture, livestock, fisheries, trade and home industries and services sectors. Pageraji Village has a lot of village potential in terms of culture, tourism, culinary, local wisdom and others. However, the potential of Pageraji Village has not yet been raised because it has not found the most appropriate media to support the existing potential. Currently Internet users in Indonesia are more than 50 percent or around 143 million people throughout 2017 according to the latest report by the Indonesian Internet Service Providers Association (APJII). The majority of internet users as much as 72.41 percent are still from urban communities. Pageraji.info Web Portal to support the potentials in Pageraji Village both in terms of culture, tourism, culinary, local wisdom and others. Enabling the potential of Pageraji Village can be lifted well because there is the most appropriate media to support the existing potential.
\end{abstract}




\section{Korespondensi:}

dataran tinggi yang berbatasan dengan sebelah Utara Desa Langgongsari, sebelah Timur Desa Langgongsari dan Desa Pejogol, sebelah Selatan Desa Jatisaba, Desa Kasegeran dan Desa Sudimara, sebelah Barat Desa Cilongok dan Desa Pernasidi. Kondisi perekonomian Desa Pageraji saat ini ditopang oleh sektor pertanian, peternakan, perikanan, perdagangan dan industri rumah tangga dan jasa. Desa Pageraji mempunyai banyak potensi Desa baik dari sisi budaya, wisata, kuliner, kearifan lokal dan lain-lain. Namun potensi Desa Pageraji, masih belum terangkat karena belum menemukan media yang paling tepat untuk menunjang potensi yang ada. Saat ini pengguna Internet di Indonesia lebih dari 50 persen atau sekitar 143 juta orang sepanjang 2017 menurut laporan teranyar Asosiasi Penyelenggara Jasa Internet Indonesia ( APJII). Mayoritas pengguna internet sebanyak 72,41 persen masih dari kalangan masyarakat urban. Dari permasalahan yang ada kami menawarkan Web Portal Pageraji.info untuk menunjang potensi-potensi yang ada di Desa Pageraji baik dari sisi budaya, wisata, kuliner, kearifan lokal dan lain-lain. Sehingga potensi Desa Pageraji, dapat terangkat dengan baik karena adanya media yang paling tepat untuk menunjang potensi yang ada.

\section{Trias Bratakusuma}

Program Studi Sistem Informasi, Universitas Amikom Purwokerto Jl. Letjend Pol Sumarto, Karangjambu, Purwanegara, Purwokerto Utara, Banyumas, Indonesia

\section{PENDAHULUAN}

Web Portal adalah website yang menjadi pintu gerbang starting point bagi pengunjung untuk memulai aktivitasnya di Internet (Asosiasi Penyelenggara Jasa Internet Indonesia/APJII., 2018; Erick, P., Rumani, M., Andrew, 2015). Web Portal yang bersifat horizontal menyediakan berbagai informasi dan layanan umum(Hakim, 2013). Web portal dapat digunakan untuk mengangkat potensi Desa Pageraji, Kecamatan Cilongok, Kabupaten Banyumas. Desa Pageraji terletak di sebelah Barat Ibu Kota Kabupaten Banyumas dengan jarak kurang lebih $9 \mathrm{~km}$ dan terdiri atas daerah dataran rendah dan dataran tinggi yang berbatasan dengan sebelah Utara Desa Langgongsari, sebelah Timur Desa Langgongsari dan Desa Pejogol, sebelah Selatan Desa Jatisaba, Desa Kasegeran dan Desa Sudimara, sebelah Barat Desa Cilongok dan Desa Pernasidi. Secara administratif Desa Pageraji termasuk dalam wilayah Kecamatan Cilongok dan berjarak kurang lebih $3 \mathrm{~km}$ dari Ibu Kota Kecamatan. Secara kewilayahan Desa
Pageraji terdiri atas 3 dusun, 10 Rukun Warga (RW) dan 59 Rukun Tetangga (RT). Luas Desa Pageraji adalah 640,565 hektar (Ha.) atau 6,4 $\mathrm{Km}^{2}$.

Jumlah penduduk Desa Pageraji keadaan sampai dengan 31 Desember 2018 sebanyak 10.596 jiwa. Kondisi perekonomian Desa Pageraji saat ini ditopang oleh sektor pertanian, peternakan, perikanan, perdagangan dan industri rumah tangga dan jasa. Desa Pageraji mempunyai banyak potensi desa baik dari sisi budaya, wisata, kuliner, kearifan lokal dan lain-lain. Namun potensi Desa Pageraji, masih belum terangkat karena belum menemukan media yang paling tepat untuk menunjang potensi yang ada (R, 2005; Sirait, 2002; Siswanto, 2005; Tangkilisan, 2005; Widjaya, 2008).

Saat ini pengguna Internet di Indonesia lebih dari 50 persen atau sekitar 143 juta orang sepanjang 2017 menurut laporan teranyar Asosiasi Penyelenggara Jasa Internet Indonesia (Asosiasi Penyelenggara Jasa Internet Indonesia/APJII., 2018). Mayoritas pengguna 
internet sebanyak 72,41 persen masih dari kalangan masyarakat urban. Berdasarkan wilayah geografisnya, masyarakat Jawa paling banyak terpapar internet yakni 57,70 persen, selanjutnya Sumatera 19,09 persen, Kalimantan 7,97 persen, Sulawesi 6,73 persen, Bali-Nusa 5,63 persen, dan Maluku-Papua 2,49 persen (Asosiasi Penyelenggara Jasa Internet Indonesia/APJII., 2018).

Dari permasalahan yang ada kami menawarkan Web Portal Pageraji.info untuk menunjang potensi-potensi yang ada di Desa Pageraji baik dari sisi budaya, wisata, kuliner, kearifan lokal dan lain-lain. Sehingga potensi
Desa Pageraji, dapat terangkat dengan baik karena adanya media yang paling tepat untuk menunjang potensi yang ada.

\section{METODE PELAKSANAAN}

Menguraikan bentuk kegiatan pengabdian kepada Pelaksanaan akan dilaksanakan oleh tim pelaksana yang terdiri dari tiga orang, yaitu ketua dan anggota dari dosen tetap STMIK Amikom Purwokerto. Kualifikasi tim pelaksana kegiatan program ini adalah sebagai berikut:

1) Memiliki pengalaman kerja dan mempunyai kemampuan dalam

Tabel 1. Langkah Penyelesaian Masalah

\begin{tabular}{|c|c|c|c|}
\hline No & Kegiatan & Partisipasi Pengabdi & $\begin{array}{l}\text { Partisipasi Khalayak } \\
\end{array}$ \\
\hline 1 & Analisa Proses Bisnis & $\begin{array}{l}\text { - Memahami kebutuhan } \\
\text { Website Portal yang akan } \\
\text { dibangun. } \\
\text { - Mewawancarai } \\
\text { masyarakat Desa Pageraji. } \\
\text { - Mengumpulkan informasi } \\
\text { dan melakukan analisa } \\
\text { tentang potensi Desa yang } \\
\text { bisa diangkat di website. } \\
\text { - Mencari data pendukung }\end{array}$ & Informan Menyediakan data dukung \\
\hline 2 & $\begin{array}{l}\text { Penyesuaian Desain Aplikasi } \\
\text { dengan proses bisnis }\end{array}$ & Mendesain aplikasi & \\
\hline 3 & $\begin{array}{l}\text { Penyesuaian Code Aplikasi } \\
\text { dengan proses bisnis }\end{array}$ & $\begin{array}{l}\text { Melakukan kodefikasi } \\
\text { Pembelian Domain } \\
\text { Sewa Hosting }\end{array}$ & \\
\hline 4 & $\begin{array}{l}\text { Pengetesan Aplikasi apakah } \\
\text { sudah sesuai dengan proses } \\
\text { bisnis }\end{array}$ & $\begin{array}{l}\text { - Melakukan testing } \\
\text { aplikasi. } \\
\text { - Kroscek penyesuaian } \\
\text { bersama khalayak }\end{array}$ & $\begin{array}{l}\text { Mencoba aplikasi sambil melakukan } \\
\text { kroscek apakah aplikasi sudah sesuai } \\
\text { dengan proses bisnis }\end{array}$ \\
\hline 5 & Instalasi aplikasi & Melakukan instalasi aplikasi & $\begin{array}{l}\text { Menyediakan tempat dan perangkat } \\
\text { komputer untuk instalasi. }\end{array}$ \\
\hline 6 & $\begin{array}{l}\text { Pembentukan Struktur } \\
\text { Organisasi }\end{array}$ & $\begin{array}{l}\text { Membentuk kelompok } \\
\text { informasi masyarakat }\end{array}$ & $\begin{array}{l}\text { Menyiapkan diri agar dapat } \\
\text { mengoptimalkan pengguna website } \\
\text { portal yang telah dibuat. }\end{array}$ \\
\hline 7 & Pelatihan dengan Materi & $\begin{array}{l}\text { Pelatihan dasar-dasar } \\
\text { jurnalistik. } \\
\text { - Konteks management } \\
\text { sistem dengan wordpress. } \\
\text { - Pengenalan dasar-dasar } \\
\text { SEO. } \\
\text { - Sudah online dan dapat } \\
\text { diakses. }\end{array}$ & $\begin{array}{l}\text { Mengikuti dan memahami materi } \\
\text { pelatihan tentang dasar jurnalistik, } \\
\text { konteks management sistem dengan } \\
\text { wordpress, paham pentingnya SEO } \\
\text { untuk meningkatkan pengunjung di } \\
\text { website portal Desa Pageraji. } \\
\text { Seluruh masyarakat dapat mengakses. }\end{array}$ \\
\hline
\end{tabular}


bidang teknologi informasi.

2) Mampu melakukan analisa dan desain sistem informasi

3) Mampu menyusun database sebuah sistem

4) Mampu melakukan pengkodean untuk menghasilkan sebuah Sistem informasi

5) Kemampuan pemyampaian materi yang bagus dan mudah dipahami.

Pelaksanaan kegiatan Pengabdian Pada Masyarakat ini dilakukan dengan menggunakan metode seperti pada Tabel 1 .

\section{HASIL DAN PEMBAHASAN}

\subsection{Hasil Kegiatan}

Dihasilkan pada kegiatan pengabdian masyarakat ini adalah sebagai berikut:

1) Masyarakat mampu mengakses website portal pageraji.info.

2) Admin mampu mengelola potensi desa yang akan diposting.

3) Mampu memahami SEO dasar.

4) Menyediakan website portal pageraji.info yang telah diterapkan berupa aplikasi berbasis website.

\subsection{Pembangunan Aplikasi}

Pada Gambar 1 berisi Recent Post, Mampu menampilkan postingan baru yang mampu mengangkat potensi desa, misalnya di bidang seni dan budaya, layanan publik, pemberdayaan masyarakat, agama, olahraga, peta pageraji, hubungi kami dan arsip Desa Pageraji.

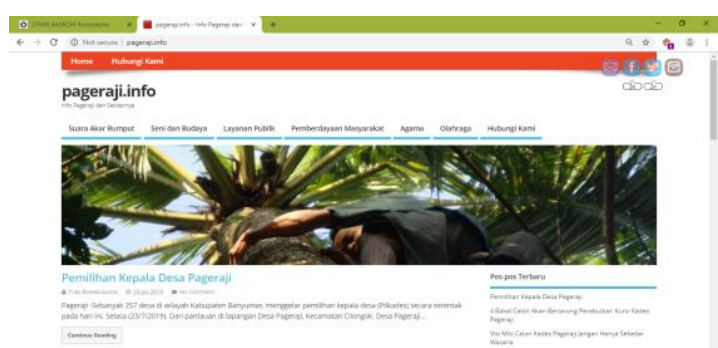

Gambar 1. Halaman Recent Post

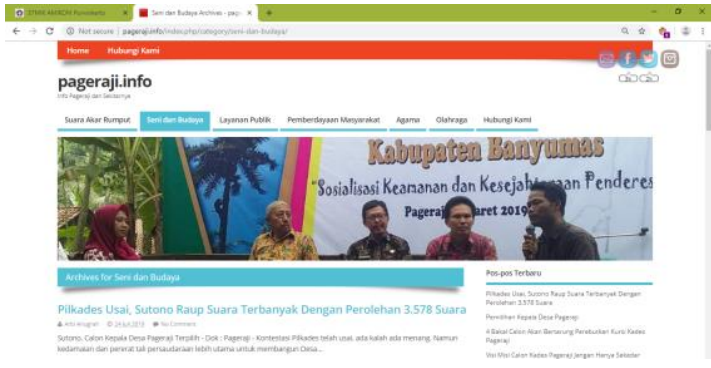

Gambar 2. Halaman Seni dan Budaya

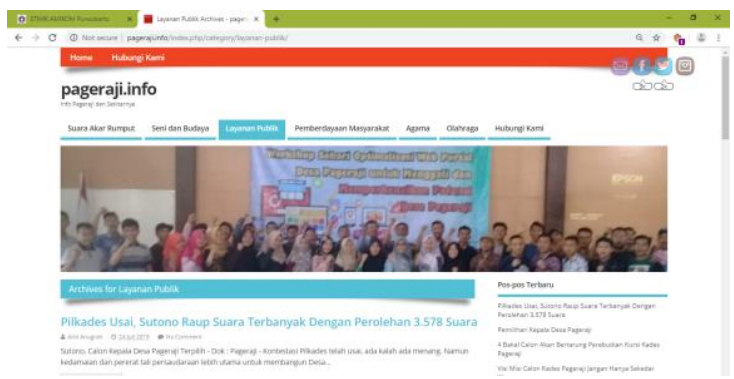

Gambar 3. Halaman Layanan Publik

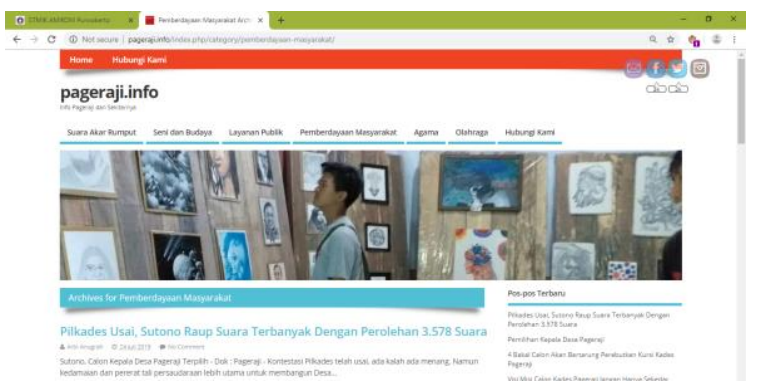

Gambar 4. Pemberdayaan Masyarakat

Pada Gambar 2 berisikan artikel yang mengangkat seni dan budaya apa saja yang ada di Desa Pageraji. Misalnya pada konten festival anak NU 2019, warga Desa Pageraji Antusias nonton bareng capres dan cawapres, "tour kebudayaan" embrio bersatunya komunitas pemuda lintas Desa, dan bersatunya komunitas di Banyumas "Tour Kebudayaan". Tampilan pada Gambar 3 berisikan artikel dan konten tentang layanan publik yang ada di Desa Pageraji, semua berita atau informasi terbaru, misalnya tentang tentang pemilihan kepala desa yang membahas dari segi visi dan misi hingga informasi siapa yang terpilih menjadi kepala desa Desa Pageraji saat ini.

Tampilan pada Gambar 4 membahas tentang empak aspek pemberdayaan 
masyarakat untuk meningkatkan kemampuan dan kemandirian melalui aspek perlindungan sosial, peningkatan kapasitas, peningkatan aksesibilitas dan pemanfaatan potensi lokal. Contohnya pembuatan gula aren di Desa Pageraji, dan lainnya. Pada Tabel 5 membahas tentang kegiatan di Desa Pageraji di bidang keagamaan, yaitu mengadakan pengajian yang diikuti oleh masyarakat Desa Pageraji dan sekitarnya.

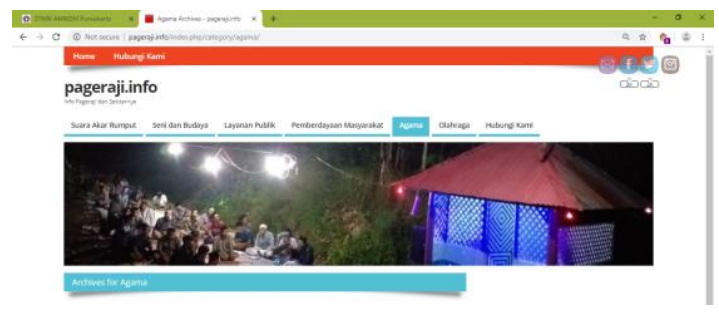

Gambar 5. Halaman Agama

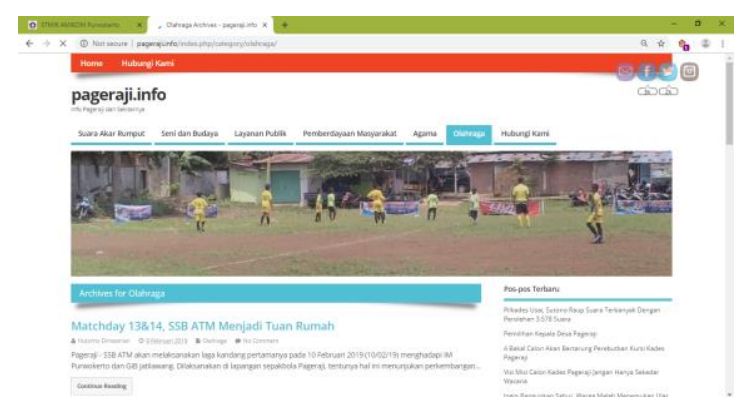

Gambar 6. Halaman Olahraga

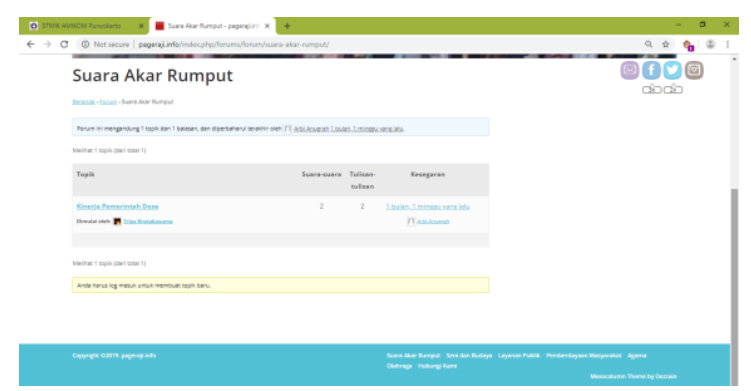

Gambar 7. Halaman Suara Akar Rumput

Selanjutnya adalah Gambar 6 disini berisikan informasi-informasi seputar olahraga di Desa Pageraji, terutama dibidang olahraga sepak bola, dengan team unggulan Desa Pageraji ATM. Untuk Gambar 7 merupakan tampilan mengenai suara akar rumput, adalah wadah untuk berdiskusi tentang apa yang ingin di bahas di Desa Pageraji. Misalnya dalam forum online mengkritisi visi dan misi pemilihan kepala Desa Pageraji, seluruh masyarakat dapat bergabung dalam forum ini. Masyarakat dapat mengetahui dan mengkritisi visi dan misi yang di sampaikan oleh calon kepala Desa, dan bisa dijadikan pertimbangan bagi masyarakat dalam memilih kepala Desa, yang mempunyai visi dan misi yang baik untuk kemajuan Desa Pageraji. Di forum ini bebas membahas topik apa saja, dan dapat diikuti oleh siapa saja, terutama masyarakat Desa Pageraji.

Fasilitas Kotak Saran pada Gambar 8 untuk memberikan saran dalam membuat topik di forum diskusi, apa yang ingin dan akan di bahas dalam forum selanjutnya. Khusus untuk halaman pada Gambar 9, menampilkan pospos terbaru di website portal Pageraji.info.

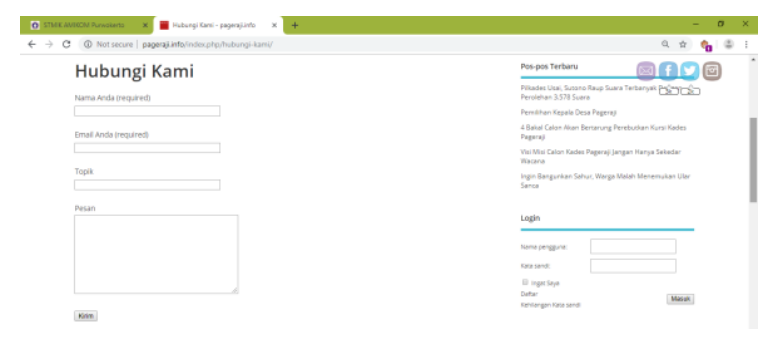

Gambar 8. Halaman Kotak Saran

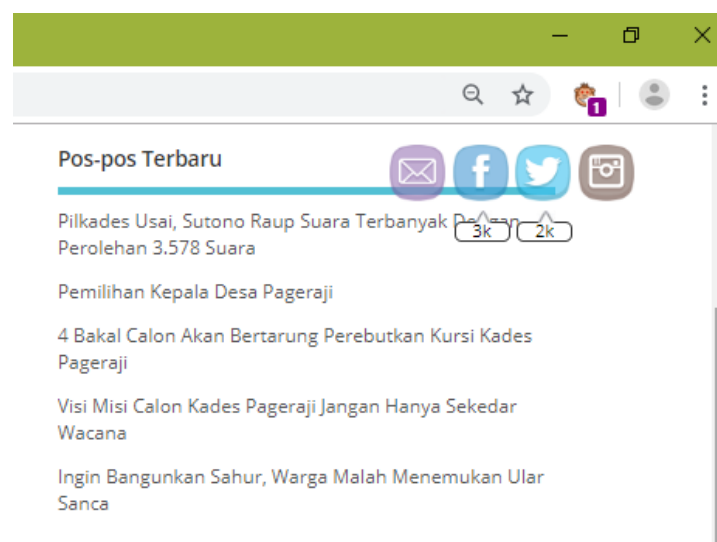

Gambar 9. Halaman Pos-pos Terbaru 


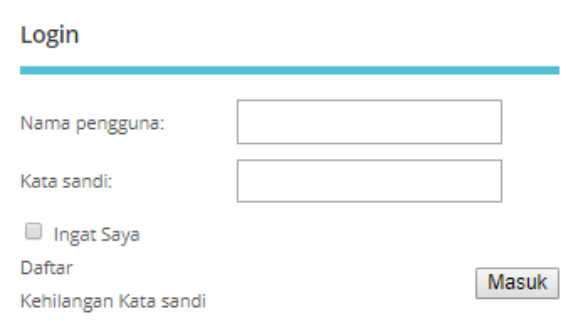

Gambar 10. Halaman Pos-pos Terbaru

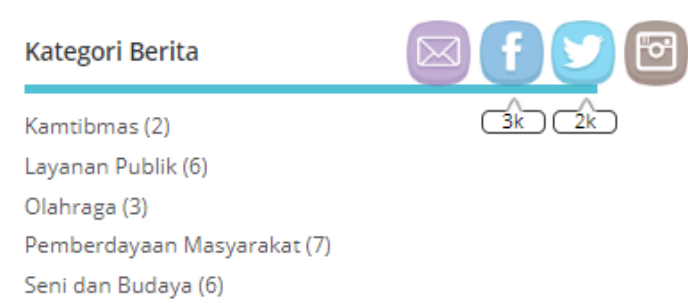

Gambar 11. Halaman Kategori Berita

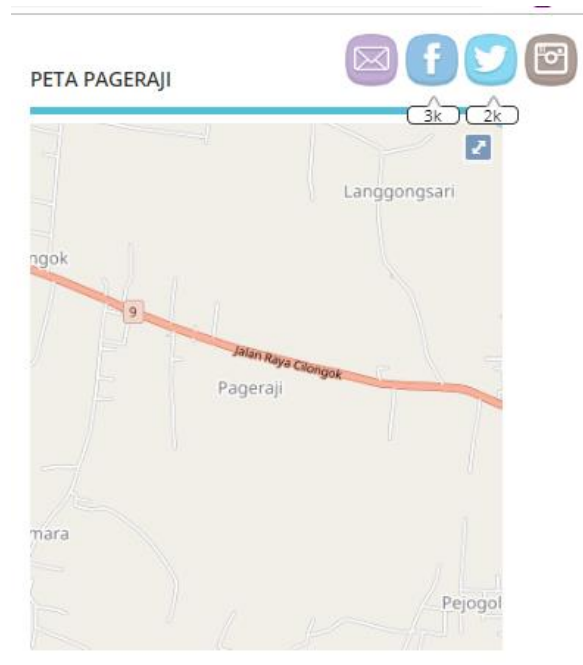

Gambar 12. Halaman Peta Desa Pageraji

Form Login diperlihatkan Gambar 10, disini berisikan form untuk login, dengan memasukkan nama pengguna, kata sandi, dan bergabung masuk ke website portal Desa Pageraji.

Pada Gambar 11 menampilkan kategori berita yang ada di Desa Pageraji diantaranya kamtibnas, layanan publik, olahraga, pemberdayaan masyarakat, dan seni dan budaya. Fasilitas tambahn lainnya adalah Peta
Desa Pageraji pada gambar 12 yang memberikan informasi dimana letak Desa Pageraji.

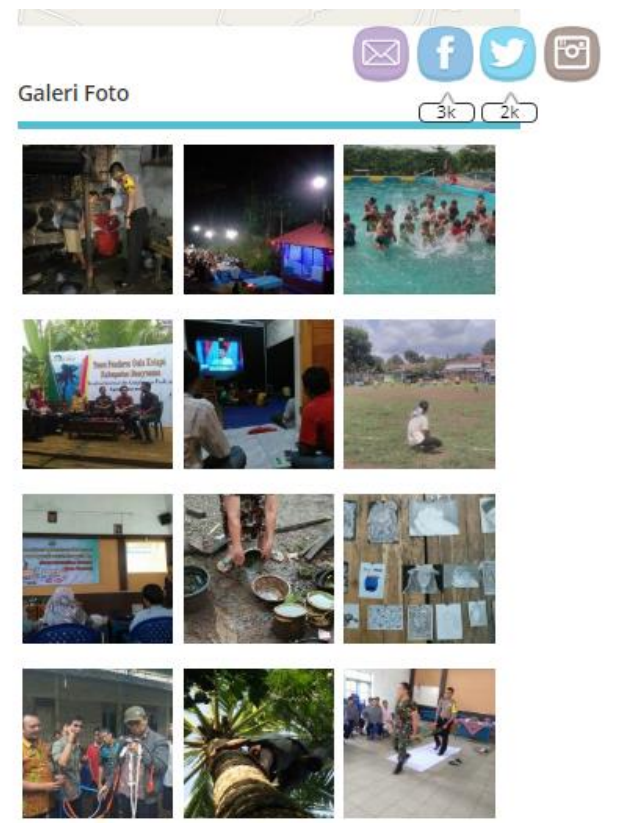

Gambar 13. Halaman Galeri Foto

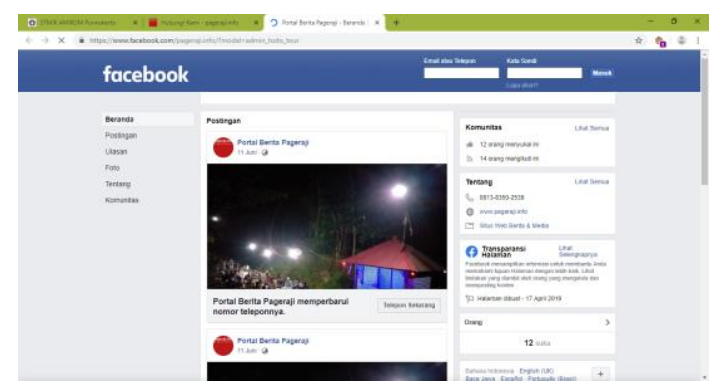

Gambar 14. Halaman Facebook Desa

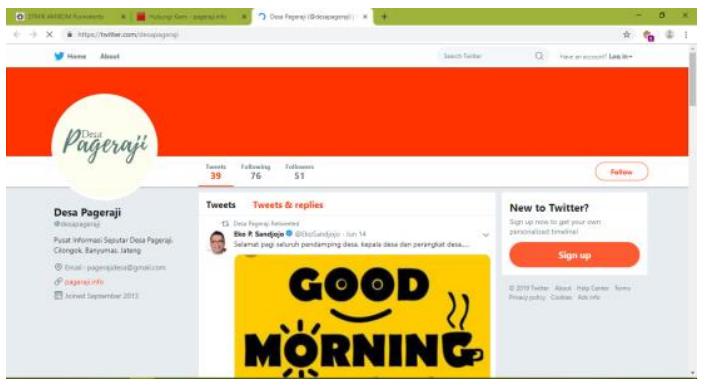

Gambar 15. Halaman Twitter Desa

Galeri Foto Desa Pageraji yang terdapat pada Gambar 13 berisi foto-foto kegiatan yang 
ada di Desa Pageraji, dari bidang olahraga, agama, dan lainnya. Gambar 14 dan Gambar 15 berisi Media Sosial Facebook dan Twitter Desa Pageraji, Desa Pageraji memiliki media sosial facebook disini juga berisikan kegiatankegiatan yang dilakukan masyarakat Desa Pageraji. Selain facebook, Desa Pageraji juga mempunyai akun twitter, gunanya sebagai wadah untuk diskusi.

\section{KESIMPULAN}

Berdasarkan pemaparan, maka dapat diambil kesimpulan bahwa, website portal Pageraji.info mampu mengangkat potensi Desa yang ada. Kelengkapan fasilitas website portal mampu menciptakan ketergantungan bagi pengunjung agar secara reguler datang ke website Pageraji.info. Lambat laun masyarakat akan tertarik untuk menjadi member dan menjadikan portal tersebut halaman pertama setiap kali membuka Internet browsernya.

Portal dibangun sebagai one stop services bagi pengunjung. Sehingga orang menjadi betah menelusuri isinya. Saran bagi pemerintah Desa Pageraji selanjutnya adalah dengan megupdate terus portingan-postingan kegitankegiatan, maupun potensi desa yang belum terangkat, sehingga website ini dapat digunakan secara evektif dan efisien. Diharapkan pemerintah Desa yang mengelola website ini dapat memahami dengan baik SEO, sehingga bisa menaikan trafik di mesin pencarian google.

\section{UCAPAN TERIMA KASIH}

Ucapan terima kasih penulis ucapkan untuk Universitas Amikom Purwokerto yang telah mendukung pengabdian ini

\section{DAFTAR PUSTAKA}

Asosiasi Penyelenggara Jasa Internet Indonesia/APJII. (2018). Penetrasi Internet di Indonesia Capai 143 Juta Jiwa.

Erick, P., Rumani, M., Andrew, O. (2015). Pengaplikasian dan Perancangan One Stop Shoping Portal Berbasis Website (Interface Konsumen). E-Proceeding of Engineering.

Hakim, Z. (2013). Pengertian Web Portal.

R, B. (2005). Interakasi Desa dan Kota serta permasalahannya. PT Gramedia.

Sirait, F. A. \&. (2002). Pembangunan berwawasan Lingkungan,. Pradnya paramita.

Siswanto, J. (2005). Administrasi Pemerintahan Desa. CV Rajawali Jakarta.

Tangkilisan, H. N. S. (2005). Kebijakan dan Manajemen Otonomi Daerah. Lukman Ofset.

Widjaya, H. (2008). Otonomi Desa merupakan otonomi yang asli bulat dan utuh. PT Raja Grafindo Persada. 